\title{
Exploration of Colour from Wine Bottles and Top Waste to Allegorize Wine Carrying Rites of Igbo Culture
}

\author{
Osamudiamen O. IKponmwosa \\ Department of Fine and Applied Art \\ Federal College of Education (Technical) \\ Asaba, Delta State, Nigeria \\ E-mail: osusikponmwosa@gmail.com \\ Phone: 09026545162 \\ Awele G. Adingwupu \\ Department of Fine and Applied Art \\ School Art and Design \\ Delta State Polytechnic \\ Ogwashi-Uku, Delta State, Nigeria \\ E-mail: gabreilawele@gmail.com \\ Phone: 07065123020
}

\begin{abstract}
This research used bottle wastes (tops and body) to explore the possibility of invalidating the school of thought's and misleading viewpoints that a painting cannot be fully executed without traditional colour pigments. Also, waste management was another aspiration of this study. To achieve the aforementioned objectives, wine carrying rites in Igbo culture was used as an allegory, with the bottle wastes as media. Wastes, ranging from materials (wood, plastic, glass, metal, etc.) are among the factors that are considered as problem to environment. The challenges therein include their large quantity, very low biodegradability and continuous generation due to everyday activities. Interestingly, discovery of alternative methods of marshaling these wastes via friendly methods have become one of the major research issues. The experiment was therefore done by using bottle wastes for mosaic. The results reveal that paintings could still be done without using colour pigments. It recommended that more visual studies should be conducted to explore the potential of other non-pigment materials. Moreover other friendly methods could be implored by artist to manage wastes for positive impact.
\end{abstract}

Keywords: waste; painting; bottle; mosaic; cement; disposal.

Keywords: Learning, pedagogy, advanced research techniques, Research methods, Students

Aims Research Journal Reference Format:

Osamudiamen O.Ikponmwosa \& Awele, G. Adingwupu (2018): Exploration of Colour from Wine Bottles and Top Waste to Allegorize Wine Carrying Rites of Igbo Culture. Advances in Multidisciplinary \& Scientific Research Journal. Vol. 4. No.1, Pp 8-16

\section{INTRODUCTION}

Traditional marriage in Africa is a ceremony consummated not only to join a man and the woman together, but also to join two families and village together. In the days gone past, parents contract a marriage affair on behalf of their son or daughter now days, a man is free to bring home anyone in as much as the parents approve of the lady and vice vassal. Seeman (2004) asserted that traditional marriage in lgbo land is giving out a girl that has matured to marry, to the suitor when the suitor comes. the parents of the bride will hand the girl over to the suitor who is accompanied by his parents and well-wishers after doing the traditional marriage rituals that are involved. Wine carrying known as "Igba Nkwu" in the Igbo language is an important part of tradition marriage ritual in Igbo land whereby the bride presents the groom with a cup filled with palm wine. Emenike (1990) believes that this ritual symbolizes that acceptance of the groom by the bride. To this end the wine carrying ritual ("Igba Nkwu") play a significant and symbolic role in traditional marriage in Igbo land. The use of colour pigment for artistic expression in Africa can probably be traced back to around 7,000 years ago. Clarke (2013) asserted that the rock paintings which are found throughout the African continent most especially the Saharan region possibly dates back to 8000 B.C. 
However, there are other significant examples of rock paintings that have also been found in the eastern and southern part of Africa. African artists used naturally derived pigments, such as ocher and indigo to mention but a few to produce their paintings. According to Clarke (2013) paint became a very popular medium among artists from the twentieth century. In Nigeria today however, commercially produced paints are now extensively been used to produce works of art, as revealed by the vernacular sign paintings and the works of academically trained contemporary artists. A lot of scholarly works are available on Pigment as one of the essential components of paint.

Presently however, innovation in painting among academically trained contemporary artists in Nigeria are now beginning to place more emphasis on the exploration of the environment as a potential source for creative ideas, materials and forms. This has in no small way led to a number of experiments that requires the use of alternative media for producing various art forms (Ghosh et al., 1990; Murray, 2007; Clark, 2013).Presently, such paradigm shift is ongoing in many art schools as visual art research areas. For instance Okoro, (2013) discussed about earth pigments which can serve as supports, ground or media and are aesthetically appealing, highly innovative and far cheaper to acquire than conventional painting materials. He also confirmed that in the area of painting, the use of clay another earth pigments for media, ground and supports are clearly the resultant effects and the gain of restless search for down - to - earth materials for painting. These types of experimentation is what has become known as "Exploration of Indigenous Ideas, Forms and Materials in Painting" (Oloidi and Akwanya, 2006).

This is also a reflection of a creative ideology that is consistently been driven by the exploration and appropriation of culture-based art forms as a viable creative resource for visual expression. Okoro (2013) emphasized that such exploration of the environment as potent sources of ideas, materials and forms offers a creative pathway that energizes the creative spirit.. Clarke (2013) observed that African artists use many other kinds of materials in the creation of paintings. He further observed that beads are used throughout much of Africa. Many kinds of beads, mainly those made of seeds, shells, bone, or coral, are locally available for making of prestige objects. Clarke (2013) also stated that glass beads, which are of Indian or European origin animal hide, are also used to create visually appealing art works.

The utilization of these materials in Africa for producing artworks reveals that colours found from other sources other than pigments can also be effective in art work production. This calls attention to the need to explore into the use of recycled non-pigment material like discarded broken bottle and their caps to produce a painting.

\subsection{Statement of the Problem}

The faulty and misleading popular viewpoints that say without traditional colour pigments a painting cannot be fully executed needs to be proven. Moreover, recent research findings in painting seem to indicate that a paradigm shift from the formalistic painting tradition to a more creative pragmatic and innovative approach is feasible. This in turn underscores the need to explore into the use of non-pigment material as a medium for painting. The problem of this study is stated below:

1. To what extent can discarded bottles and their covers be used as non-pigmented medium in painting?

2. How effective can these wastes be utilized as medium in making visual commentaries as well as document cultural rites such as the "wine carrying" in Igbo marriage?

\subsection{Purpose of the Study}

The purpose of the study was to explore discarded bottles and their lids as possible painting materials by recycling and utilizing them to reduce their nuisance as well as prove their viability as non-pigmented material for painting in order to document the wine carrying rites in the Igbo traditional marriage culture of Nigeria. More specifically, the objectives are to:

1. Ascertain if non-pigment materials from within the immediate environment can serve as media for painting.

2. Discover the possibility of recycling waste material such as discarded broken bottle and their cover as a medium for painting.

3. Explore the potential of these non-pigment materials from within the immediate environment in the visual documentation of the wine carrying rites in the Igbo traditional marriage culture.

\subsection{Research Questions}

The following research question will be raised for this study:

1. To what extent can non-pigment materials from within the immediate environment serve as media for painting?

2. To what extent can waste materials such as discarded broken bottle and their cover be utilized as a medium for painting?

3. What are the potential of utilizing these non-pigment materials from within the immediate environment to visually document the wine carrying rites in the Igbo traditional marriage culture? 


\subsection{Significance of the study}

The study is important in the following ways:

- The result of the findings will serve as bases for further research, and contribute to literary presentation in visual arts, which is aimed at addressing exploration of non-pigment materials in painting. The information and data obtained would be most useful to departments in universities, polytechnics and colleges of Education, which offer the fine art programmes.

- This research will provide relevant information on the exploration of non-pigment materials in painting. Such knowledge will provide contemporary artists with other alternative media than the conventional traditional media for painting.

- The study will also help to encourage as well as foster environmentally friendly behaviour through recycling of waste materials such as broken bottle and their cover.

- Finally, the study will make artists, aware of the availability of alternative media for painting within the immediate environment, as well as erase the impression that arts media is restricted to pigment colours alone.

\section{RESEARCH METHODOLOGY}

This is an experimental research design was employed study that was carried out to determine whether recycling waste material such as discarded broken bottle and their cover can be utilized in executing a painting. This study was not only used to emphasis visual forms that depicted the wine carrying rites in the Igbo traditional marriage culture but also focused on the utilization of non- pigment materials in the execution of the painting project. A multifaceted methodological approach was utilized in investigating the visual property and the underlining socio-cultural meaning of the wine caring rites in the Igbo traditional marriage culture. To this end library research, interview, participant observation, including audio-visual documentation was put to use to gather the required data. In addition, preliminary sketches and colour study of the wine caring rites in the Igbo traditional marriage culture was done. Furthermore, a large quantity of broken bottle and their cover (non-pigment media) was collected and used to produce the finally painting project.

\subsection{Working Drawing}

Three preliminary sketches (plate 1, 2 and 3) were done, in which one was selected.

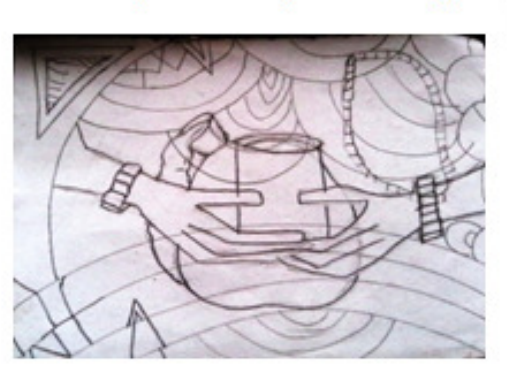

Plate 1

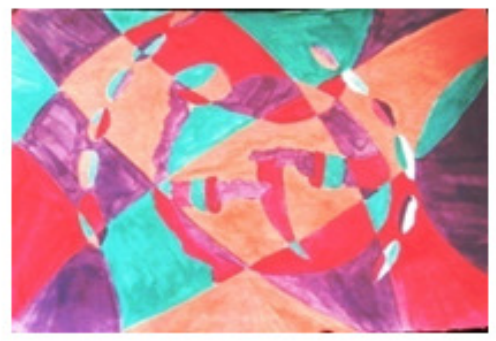

Plate 4

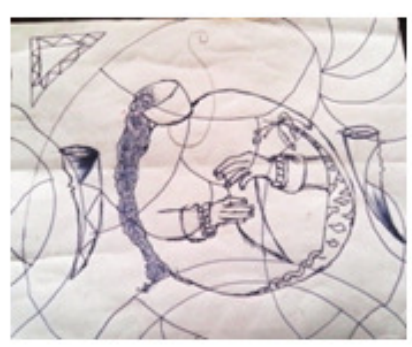

Plate 2

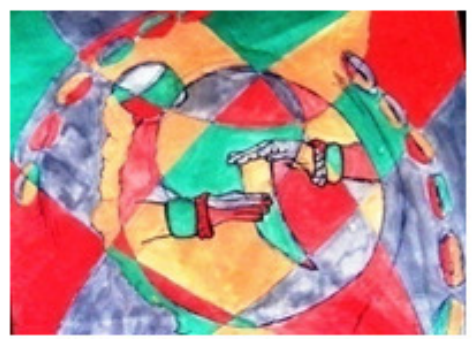

Plate 5

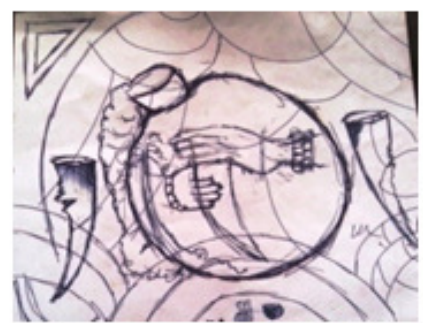

Plate 8

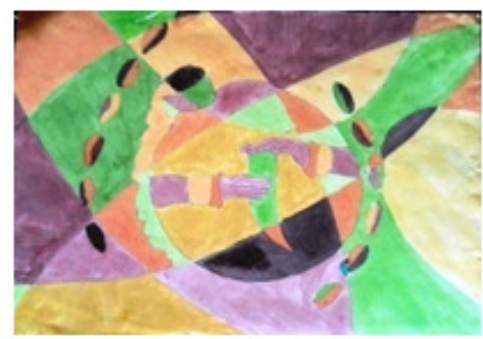

Plate 6 


\subsection{Colour Study}

Similarly, three colour study (plate $4,5,6$ ) were also produced from which only one was finally sellected for the project. This was used to develop the working drawing in plate 7.

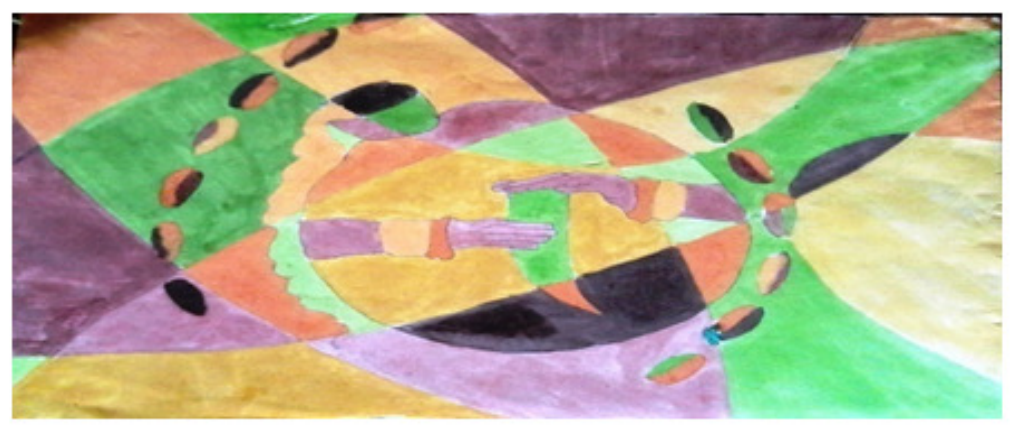

Plate 7:Working drawing

Ply wood: A ply wood of $4 \mathrm{ft}$ by $6 \mathrm{ft}$ was used as the ground for the work. It is constructed wooden material supplied in sheets, and made of three or two layers of wood, glued, together, without the plywood the work cannot be achieve. Glue: Glue was used for priming. It was also used in mixing the primer before priming. It also served as the adhesive to glue the Bottle cover, Stone, Glass on top of the plywood. Bottle covers and Broken Bottles: A large quantity of broken bottle and their cover (non-pigment media) were then collected and used to produce the finally painting project.

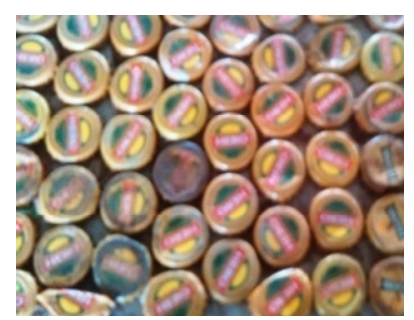

Plate 7a

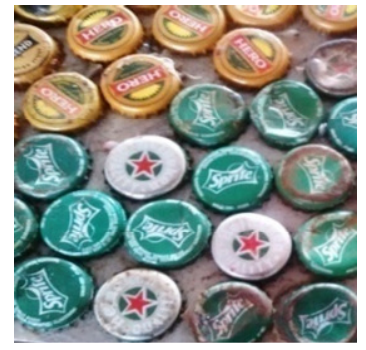

Plate $7 b$

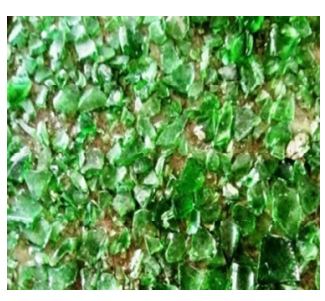

Plate 8a

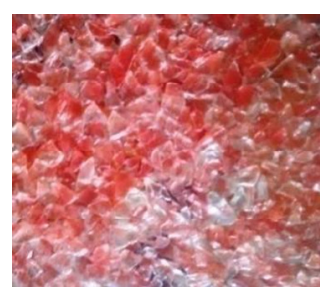

Plate 8b

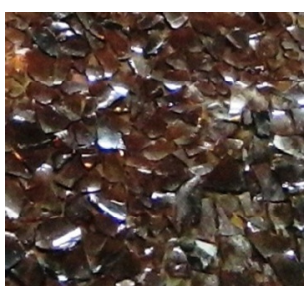

Plate 8c

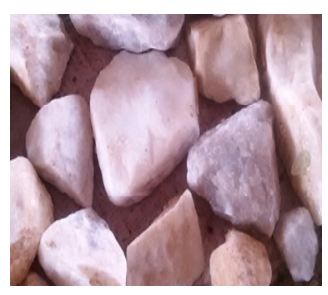

Plate 9 White gravel

Plate $8 \mathrm{a}, \mathrm{b}$ and $\mathrm{c}$ present the assorted colours of crushed/broken bottles which were used for the painting. Plate 9 is the white gravel, which were used to represent cowries. Cowries were used to symbolize wealth or abundance in the painting. Foam (for applying glue): This material was used for absolve colour and dab it on top of the stone and glass, which will then be transferred onto the plywood. 
Advances In Multidisciplinary

APs: \& S Scientific Research

Vol. 4 No. 1, March 2018

\subsection{Steps of Production}

Plate 10 to 17 presents the various steps that were employed in the production of the mosaic painting work.

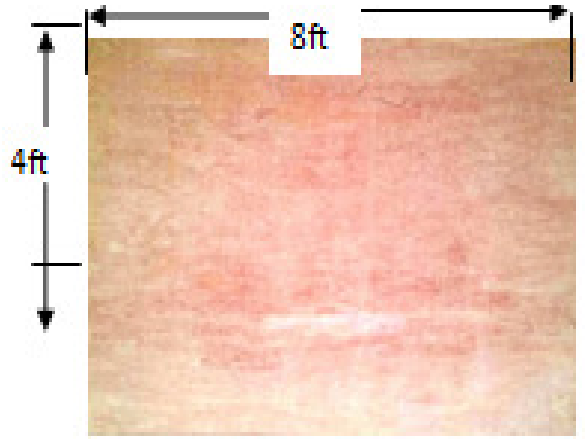

Plate 10

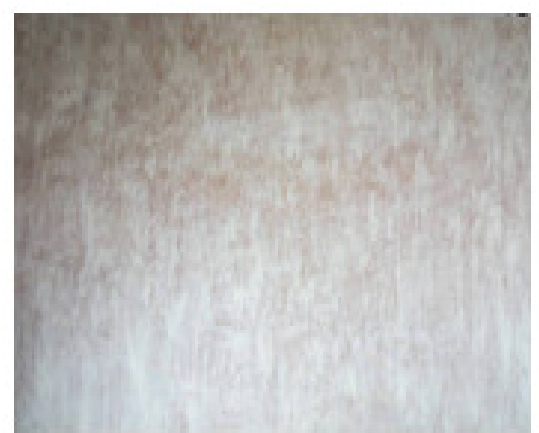

Plate 11

While plate 10 presents the ( $4 \mathrm{ft}$ by $8 \mathrm{ft}$ ) plywood which served as the support for the painting, plate 11 presents the support been primed with glue and white emulsion paint.

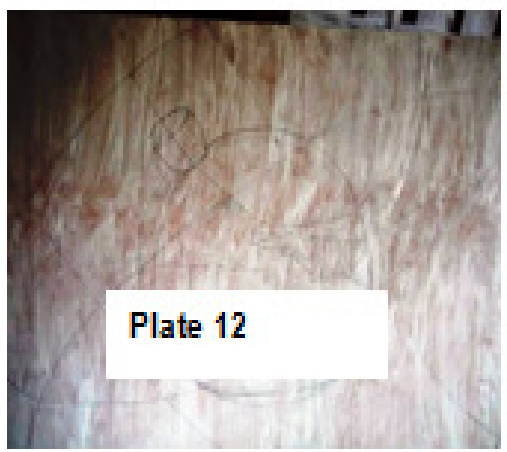

On the other hand plate 12 present the process of sketching on the support.

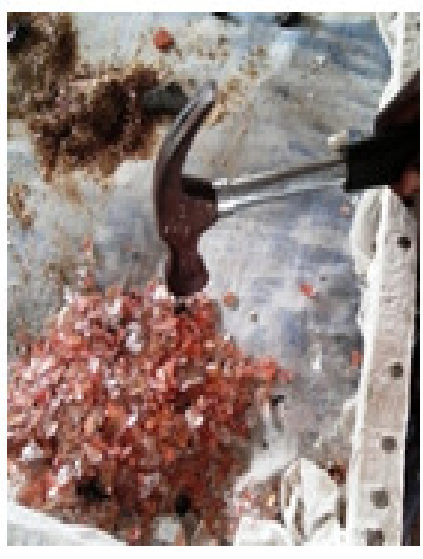

Plate $13 a$

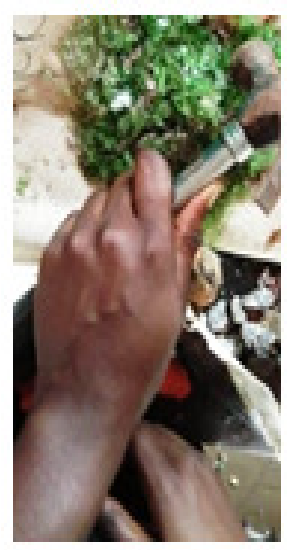

Plate $13 \mathrm{~b}$ 

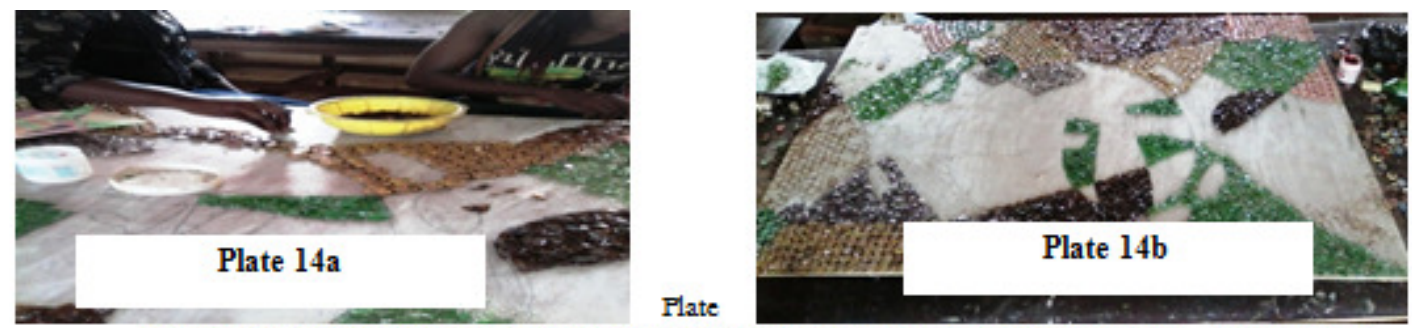

$14 \mathrm{a}$ and $\mathrm{b}$ present the stage of, attaching the bottle cover, bottle and stone on the support. These media where attached to the support with the aid of the glue. Moreover, due consideration was given to the colour theory.

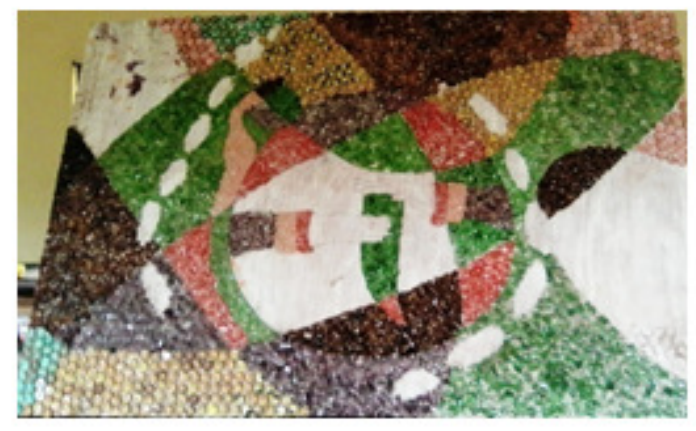

Plate 15

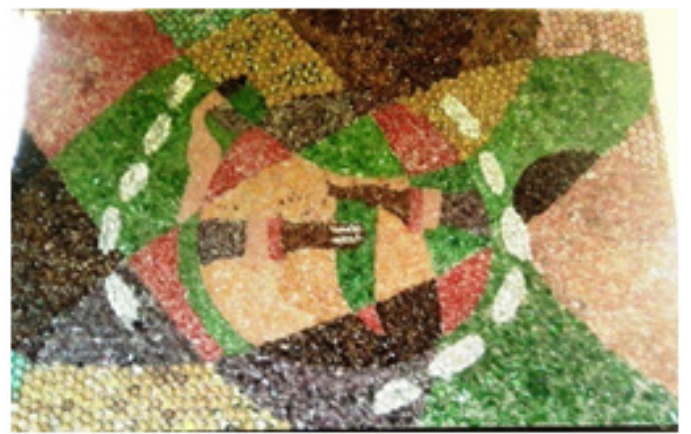

Flate 16

Plate 15 and 16 presents the concluding step of the painting. The colour scheme used was split complementary harmony, which had as its dominant colour the orange hue. Green hue was used to complement the red orange and the yellow orange hues which are both the split of parent orange hue. Given the fact that orange is a secondary colour, it then means that both red orange and the yellow orange are tertiary colours on the same analog as the parent orange. Moreover, colour of gravel which is white, served to highlight the work.

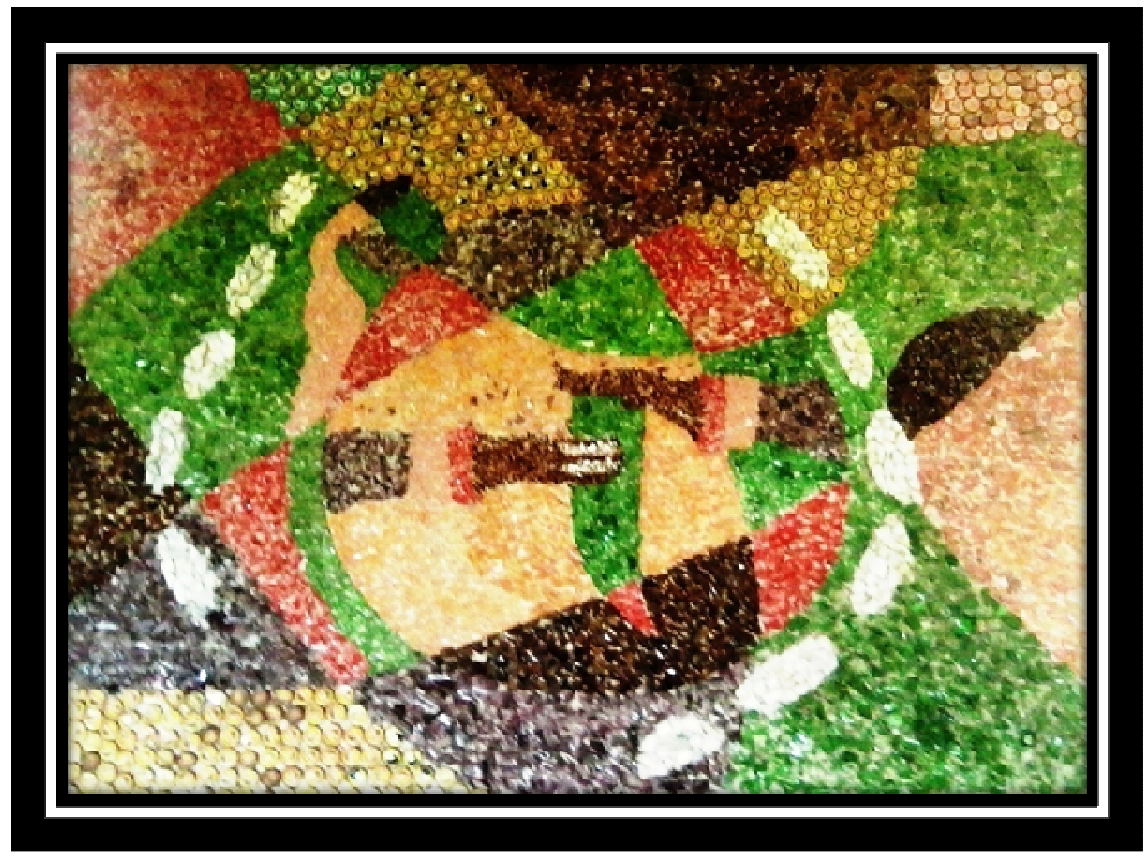

Plate 17: Final Art Work 
Plate 15 and 16 presents the concluding step of the painting. The colour scheme used was split complementary harmony, which had as its dominant colour the orange hue. Green hue was used to complement the red orange and the yellow orange hues which are both the split of parent orange hue. Given the fact that orange is a secondary colour, it then means that both red orange and the yellow orange are tertiary colours on the same analog as the parent orange. Moreover, colour of gravel which is white, served to highlight the work.

\section{DISCUSSION}

The theme of the painting is the "Wine Carrying Rites in Igbo Culture". The painting explored and recycled crushed, discarded bottles and their cover to reflected the wine carrying rites in the lgbo traditional marriage. This is an abstract painting that was rendered with tetradic (Double complementary) colour harmony scheme with a dominant orange hue. Warm colours were used to depict the happy mood of the occasion and bound of friendship. Moreover the colours were also used to portray the great expectation from the union of both families. Finally the green hue was used to symbolize fertility and abundance. It is expected that every marriage should translate into a productive and procreative experience.

In the middle of the painting is a calabash containing palm wine. Both of the bride's hands are seeing extending from both sides of the calabash and holding a horn filled with palm wine. The crushed bottles of drink (both bear and soft drinks) were symbolically used to depict the wine carrying rites in which a bride offers palm wine to the groom as a sign of acceptance. It is worthy of note to state that the use of modern drink receptacles is of significance, given the fact that there has been a strong influence of western marriage on traditional marriage, not only among the igbo speaking ethnic group but also among all the ethnic groups in Nigeria .Both bear and soft drinks are used lavishly these days, along with palm wine in traditional marriages. It is no gainsaying to say that the bottles of these modern drinks that has gained so much acceptance in recent times to celebrate traditional marriages is also the media that was used to visually express the wine carrying rites of the Igbo marriage culture. Ironically, modernity has come to the aid of tradition to document a cultural legacy.

\section{SUMMARY OF FINDINGS}

Findings revealed that:

- Non-pigment materials from within the immediate environment can serve as media for painting.

- Waste materials such as discarded broken bottle and their cover can be utilized as a media for painting.

- The potential of utilizing non-pigment materials from within the immediate environment to visually document the wine caring rites in the Igbo traditional marriage culture very high and feasible.

\section{CONCLUSION}

In conclusion, this is project focused on exploring the potential of non-pigment waste materials recycling broken bottle and their cover) from within the immediate environment, which was visually employed to document the wine carrying rites in the Igbo traditional marriage culture. Finding revealed that waste materials broken bottle and their cover recycled to produce a mosiac painting. However there is need for more visual studies towards the exploration the potential of these non-pigment media to produce other forms of painting.

\section{RECOMMENDATION}

The following recommendations were made thus:

1. The use of bottle covers, broken bottles, and stones should be experimented on other types of support other than ply wood.

2. More visual studies should be conducted towards the exploration the potential of other non-pigment materials

3. Other methods should be developed to reduce the sharp edges of the broken bottle used for the mosaic painting.

4. Other environmentally friendly methods could be implored by artist to manage wastes for positive impact such as visual storytelling 


\section{REFERENCES}

1. Clark M.D.T. (2013), Paints and pigments review. http://www.nzic. org.nz/ChemProcess/polymer/10D.pdf

2. Emenike M. (1990), Caputuring Traditional Environmental Knowledge. Canada, Ottawa: IDRC

3. Ghosh S, Warrier K.G.K. and Damodaran A.D. (1990), Thermally treated kaolin as an extender pigment. J. Mater. Sci. Letts. 9(1):1046-1048

4. Murray HH (2007), Developments in Clay Science, First Edition, Elsevier.Radarweg 1000 AE Amsterdam, The Netherlands Pp.85-94.

5. Okoro, M. N. (2013) Paradigm Shift: Local Pots and Earth Pigments as Supports, Grounds and Media for Painting in Nsukka Art School, Nigeria. International JournalofArts and Design StudiesInternational Institute for Science, Technology and Education (IISTE) vol. 9.http://www.iiste.org/Journals/

6. Oloidi, O.and Akwanya, A.N. (2006), University of Nigeria Academic Calendar, U.N.N.: U.N.N. Calendar Editorial Board.

7. Osamudiamen O. Ikponmwosa \& Awele Gabriel Adingwupu (2018): Exploration Of Colour From Wine Bottles And Top Waste To Allegorize Wine Carrying Rites Of Igbo Culture. Proceedings of the SMARTiSTEAMS Multidisciplinary Conference, February, 2018, Ogwuashi-uku, Delta State, Nigeria. Pp 750-758

8. Seeman U.E. (2004). Repositioning culture for development: women and culture development in a Nigerian rural community. community, work and family. vol. 18 334-350. 